Revista Iberoamericana. Vol. LXIII, Núms. 178-179, Enero-Junio 1997; 71-83

\title{
LIMPIA, FIJA Y DA ESPLENDOR: \\ EL LETRADO Y LA LETRA EN COLOMBIA A FINES DEL SIGLO XIX
}

\author{
POR \\ ERNA VON DER WALDE URIBE \\ Universidad de los Andes, Colombia
}

\begin{abstract}
Podría narrarse la historia de América Latina como una recíproca y contínua ocupación de terreno. No hay demarcación estable conocida por todos. Ninguna frontera fisica y ningún límite social otorgan seguridad. Así nace, y se interioriza, de generación en generación, un miedo ancestral al invasor, al otro, al diferente, venga de arriba o de abajo.

(Norbert Lechner)
\end{abstract}

Los estudios críticos del traductor, filólogo y político Miguel Antonio Caro se centran en la idea de la pureza del lenguaje. En ellos se percibe una tendencia a buscar un orden inmutable y leyes permanentes y perdurables; los guía el rechazo a innovaciones e importaciones. Sus elucubraciones sobre la lengua están constantemente intercaladas por analogías con el orden político, y la ciencia del lenguaje le sirve de sustentación de principios morales, a la vez que la moral opera como criterio para fundamentar aspectos de la lengua. Cuando redactó la Constitución de 1886, que habría de regir en Colombia por más de un siglo, se cuidó Caro de toda influencia de constituciones foráneas, tal como lo hacía en materia de lenguaje. Una de sus aspiraciones era que la obra quedara "perfecta, si vale la expresión, dentro de sus reducidos límites, para dar unidad y solidez al nuevo régimen, sin que hubiera lugar a modificaciones sustanciales en su desarrollo posterior" (Guevara citado por Torres García 49). ${ }^{1}$ Miguel Antonio Caro (1843-1909) fue el más ilustre de los presidentes gramáticos de Colombia. Su dominio de la lengua española y del latín, sumado a su habilidad como retórico, lo convirtieron en la figura dominante del campo intelectual y político del fin de siglo. Su capacidad oratoria llegaba hasta el punto de que sus contendores en el senado preparaban sus discursos y propuestas teniendo en cuenta los argumentos que Caro podría esgrimir contra ellos. Se cuenta que el general Uribe Uribe, su mayor contrincante político, secretamente tomó clases de latín para poder enfrentársele en el Senado de la República (Deas 26). En el relato que hace José Joaquín Guerra de la labor de redacción de la nueva constitución se ve claramente cómo los saberes lingüísticos de Caro le dieron toda la autoridad necesaria para imponer sus ideas en materia política (Torres García 45-54).

\footnotetext{
${ }^{1}$ Guerra fue uno de los miembros del Consejo de Delegatarios que debatió la constitución. Se presentaron varias propuestas de constitución, pero la que finalmente se aprobó fue la de Caro.
} 
Sería ingenuo creer que la fuerza de Caro residía en su habilidad para detectar un "que" galicado (una de las pesadillas de todo purista colombiano) o corregir un gerundio. Como lo señalan sus escritos literarios y filológicos, tanto como los políticos, elaboró un coherente pensamiento conservador con bases sólidas en la historia, la religión y la lengua. Sobre este edificio logró hacer su versión del discurso antiutilitarista que recorría el continente, convirtiéndolo en un coherente discurso anti-moderno. Como señala Ángel Rama, mientras los otros pensadores hacían concesiones al espíritu democrático y a cierto liberalismo, en la obra de Caro hay "una adhesión sin fisuras al catolicismo militante de la lucha antipositivista. Examinando las dos soluciones a la 'reforma social' que con más nitidez polarizaron el pensamiento del siglo XIX según su opinión, la católica y la socialista, Caro fundamentó el principio de la desigualdad, como obligada llave del orden social" (Rama, Las máscaras 19).

El movimiento que encabeza Caro, junto con el presidente Rafael Núñez, se autodenominó la "Regeneración". Su aspiración fue ordenar y unificar un país fragmentado por luchas civiles y arduas condiciones geográficas alrededor de un Estado autoritario y de la Iglesia católica. Según uno de sus más beligerantes adalides, monseñor Rafael María Carrasquilla, en el país "no hay sino dos vínculos que unen: la lengua y la religión" (citado en López 108). A pesar de su claridad ideológica, la Regeneración quedará atrapada en una fuerte contradicción. La Constitución de 1886, como señala Ligia Galvis, "es racionalista demoliberal en apariencia y escolástica en la realidad" (Galvis 223).

El nuevo régimen desea recuperar los lazos perdidos con la Iglesia católica y pocos meses antes de la publicación de $A z u l$ de Rubén Darío firma el primer concordato con el Vaticano. En el mismo momento en que, según los registros, se usa por primera vez el vocablo "modernismo", Colombia da marcha atrás en el proceso modernizador y democratizador propio de la incorporación de América Latina al nuevo orden mundial. Es casi una paradoja que sea a partir de los años noventa del siglo pasado que por fin logra incorporarse a la economía-mundial gracias a una política de cultivo y exportación del café.

Sin embargo, otra lectura de esta paradoja sería verla como característica de la Regeneración: un intento de incorporar al país a la economía-internacional, modernizando el aparato estatal, el aduanero y el fiscal, a la vez que culturalmente pone una muralla a su alrededor para evitar que entren las ideas que sustentan esa modernización en el resto del mundo. Si económicamente el proyecto de Caro no resiente el contacto con otras naciones, en el mundo de las ideas, de lo simbólico, considera que la tradición española y católica poseen todo lo que los pueblos americanos necesitan, y que debe permanecer tan pura e incontaminada como la lengua (Jaramillo Uribe 64). ${ }^{2}$

La misma modernización del aparato estatal y fiscal queda envuelta en la política de encerramiento propia de la "Regeneración". Su rasgo característico es justamente la de

\footnotetext{
${ }^{2}$ Este ensayo de Jaramillo Uribe es de 1952. En él se ve una aceptación del hispanismo proclamado por Caro, con un cambio de signo: ante el claro dominio nortemericano en el subcontinente, la idea de encontrar raíces fuertes en lo español se torna atractiva aún para los intelectuales de izquierda, que ven en esto una forma de resistencia. El discurso antiutilitarista e hispanizante será también incorporado al discurso antinorteamericano, al rechazo a la cultura de masas, a concepciones escencialistas del pueblo, etc. Para una crítica de las concepciones de pueblo y masa, ver capítulos 1 y 2 de Jesús Martín Barbero, De los medios a las mediaciones. Comunicación cultura y hegemonía.
} 
imposición de normas, restricciones, regulaciones. Se puede pensar que esto, de alguna manera, es parte de la misma "tradición de intolerancia", que según el historiador Fabio López aparece como constante en nuestra historia y se ve reforzada por la "política de abierta contención de la modernidad a través del sistema educativo" (López de la Roche 112), entregado en su totalidad a manos de la Iglesia católica.

Se plantea una contradicción, como es evidente, también en el interior de la nación misma. Un proyecto de nación que remite a la raiz hispánica y católica es un proyecto excluyente de las mayorías mestizas del país y deja de lado también la existencia de más de ochenta familias de lenguas indígenas en el territorio. Los saberes letrados, la fe católica, el hispanismo serán dominio de unos pocos que legitimarán con ello su derecho al poder. Serán efectivos en su rechazo a las ideas modernas, y privarán de ellas a todos por medio de la educación religiosa que se imparte a los pocos que tienen acceso a ella, y por la total negación de instrucción a los demás. "Puede decirse que la proyección de la Constitución de 1886 implicó la introspección de la cultura. La sociedad colombiana, en virtud de los efectos del control eclesiástico de la educación, se volvió impermeable a las ideas provenientes de las influencias positivistas y socialistas y, consecuentemente, al desarrollo de la ciencia y de la técnica. La conciencia ilustrada quedó sometida a la marginalidad cultural y a la conciencia culpable" (Galvis 236).

El discurso de la "Regeneración" tiene como base una fuerte dicotomía entre modernidad y religiosidad. Como señala Jesús Martín Barbero, a diferencia de los Estados Unidos, en donde "ser moderno no sólo equivale sino se fundamenta en ser creyente, y viceversa, en América Latina hemos vivido eso como una oposición irreductible, absolutamente maniquea" (Martín Barbero, "Secularización” 179). Así:

De un lado la modernidad será sinónimo del triunfo de la razón, de la igualdad, de la participación democrática, del progreso, y para los que piensan así la religión no es más que el pasado, lo irracional, el oscurantismo, la supervivencia de una sociedad rural, y, si me perdonan la expresión, una cosa de mujeres. Frente a los que ven de esa manera la oposición entre modernidad y religión, encontramos los del otro lado, los que miran desde la religión y que desde Pío X identificaron la modernidad con el ateísmo, con una sociedad abandonada a las fuerzas de la evolución natural, una identificación con aquellos determinismos que destruyen los valores de la tradición, del humanismo, con todo aquello que haría imposible cualquier tipo de sentido comunitario (Martín Barbero, "Secularización" 178-179).

Ésta es una clara caracterización de la polaridad que se estableció entre las dos visiones de mundo que abogaban los dos partidos políticos en Colombia. Estaba tan a la base de las polémicas que en 1909 Laureano Gómez - una de las figuras líderes del conservatismo en el siglo XX - trató de demostrar cómo un liberal no podía ser católico, ante lo cual el General Rafael Uribe Uribe - cabeza de los liberales- respondió con un famoso escrito: "De como ser liberal en Colombia no es pecado" (López 105).

Estas diferencias ideológicas entre los dos partidos políticos en Colombia durante el siglo XIX no tenían, sin embargo, mucho que ver con políticas concretas referidas a la administración, el gobierno o la inserción del país en la economía mundial. En lo económico protegían básicamente los mismos intereses (Pécaut 42). La diferencia se encontraba en el 
tipo de ideas que adoptaban para legitimar su derecho al poder. Pero después de prácticamente treinta años de régimen federal y liberal, cabe preguntarse por qué no hubo oposición de parte de claras fracciones intelectuales, ningún rechazo a la imposición de la religión católica como rectora del orden social.

Habría que preguntarse cuál era la idea de nación que se creaba y sobre qué bases, qué le antecedía, cuál había sido la experiencia de nación antes del proyecto "regenerador". Pues cabe sospechar que el proyecto de modernización llevado a cabo por los liberales desde los años cincuenta entró en claro conflicto con las formas y prácticas de las mayorías. Una clase social, supuestamente representada por un partido político —el liberal—se hizo abanderada de la modernidad. Más que querer modernizar el país, la sociedad y la economía, quiso ella modernizarse. Dentro de la enumeración que se hace de las buenas acciones del Estado liberal en el siglo XIX se cuentan la abolición de la esclavitud,el establecimiento del sufragio universal, de la libertad de industria y comercio, la libertad de prensa y de opinión, la libertad de culto, el divorcio y el estímulo del desarrollo científico y la formación de una conciencia laica (López 105). Estas disposiciones parecen ser más bien parte de las constituciones de los estados que verdaderos cambios en la sociedad. De hecho, la modernización que se quiso llevar a cabo tuvo muy pocos rasgos de aquello que asociamos con la modernidad y entró en fuerte contradicción con las estructuras sociales del país.

En los años sesenta del pasado siglo, la región de Santander, al Occidente del país, se vio favorecida por un auge de la exportación tabacalera. Ésta no trajo beneficios ni cambios para la población de la zona. Beneficiarios únicos fueron los dueños de las tierras, quienes administraron la producción desde Bogotá y se vieron sorprendidos por un decaimiento súbito de sus ingresos cuando cayeron los precios del tabaco en el mercado internacional. Con sus beneficios, los señores no modernizaron su industria agrícola, sino sus casas y enseres domésticos. Las importaciones, en las que invirtieron sus ganancias, vinieron en detrimento del artesanado local, que pidió protección al gobierno central. Éste, fiel a su política, no intervino en la libre empresa y el libre comercio de los dueños de las plantaciones.

Aquí no interesa tanto señalar la falta de visión modernizadora de los primeros "modernizadores" colombianos, como el desencuentro entre las ideas liberales por las que se abogaba y la práctica real en la que se insertaban. La "modernidad" parecía significar, en términos económicos, la inserción en la economía-mundial a través de la exportación de materias primas para así poder importar productos manufacturados, cosa en la que no se diferencia el proyecto modernizador colombiano del de los otros países latinoamericanos. Pero claramente no asumió en ningún momento la modernización de sus estructuras ni de su sociedad. Si bien tras el proyecto se encontraba una ideología de rasgos modernos, su inserción en la vida de la gente seguía los mismos patrones que venían operando desde la Colonia (Nieto Arteta 283).

Las ideas liberales parecen claramente "ideas fuera de lugar", para adoptar la denominación que les da Roberto Schwarz en el análisis de fenómenos análogos en Brasil. Las ideas que se adoptan del ideario europeo se trasladan a una realidad que las sitúa fuera de lugar. La abolición de la esclavitud es una de esas ideas, pues deja de lado el hecho de que mucho de lo que haría factible el proyecto modernizador se basa en las ventajas de precios en el mercado internacional gracias al trabajo de los esclavos. Y sin embargo, como 
anota Schwarz, aunque no se pudieran aplicar, las ideas liberales no se podían descartar (Schwarz 28). El Estado liberal adoptó gran parte de su ideario del pensamiento utilitarista de Bentham. Las ideas, sin embargo, adornaron las constituciones de los estados federales pero no transformaron a partir de ellas ni gracias a ellas la constitución de lo social en el país. Tampoco provenían de transformaciones en el orden social, como sí lo eran en el ámbito europeo de donde se tomaban prestadas. De hecho, aunque debilitada por las numerosas expropiaciones de sus bienes y sus tierras, la Iglesia católica seguía siendo la instancia más poderosa y muy seguramente la que, por razón de su orden jerárquico, más obedecía a una idea de unidad dentro del territorio nacional. Si los presidentes de las provincias no rendían cuentas al gobierno central, los prelados y obispos de las regiones sí seguían bajo la jurisdicción del arzobispo de Bogotá. La instancia que habría podido de manera más convincente impartir la idea de pertenencia a una comunidad era la Iglesia católica. A la vez, cabe sospechar que era la que podía encarnar más certeramente las ideas universales que se proclamaban también desde el liberalismo. Pero ésta se había posicionado dentro las luchas partidistas del lado del partido conservador. La fuerte identidad entre modernidad y una actitud anticatólica puede ser la que genere si no una resistencia, por lo menos una indiferencia ante las ideas liberales y modernizadoras. La población, que no se ve mayormente beneficiada por las empresas económicas del liberalismo, tenderá más claramente a un rechazo de las ideas que desde allí se defienden. Todo esto en medio de las rencillas partidistas, guerras civiles, pobreza, desazón y muerte.

Otras circunstancias de la conformación política del país pueden haber contribuido a la fuerte inserción del proyecto de los gramáticos. La presencia del Estado, en parte por las condiciones geográficas, pero también por las agitaciones políticas, siempre ha sido débil. En la mayoría de los lugares, es probable que los letrados funcionales, el cura párroco y el notario, fueran las personas que sirvieran de intermediarios entre la población y los representantes del Estado. El acceso a la letra, aunque su uso fuera deficiente, los elevaba por encima de la mayoría.

Serán Caro y sus gramáticos y prelados quienes determinarán qué es ser un católico y cuál es el castellano que se debe hablar. Rufino José Cuervo mostrará cuáles son los errores y desviaciones que alejan a miles de miles de bogotanos del acceso de la letra y del buen uso de la lengua. Él y Caro sabrán cuál es la forma correcta de decir. El bogotano corriente sabrá, desde 1867 hasta hoy, que su castellano es tan sólo una desviación de la norma y también que por eso mismo es un excluido del poder. Ni qué decir del resto del país, plagado de hablas regionales en las que incluso se escribe poesía y narrativa, pero que quedan excluidas de la verdad, de la palabra, por ser desviaciones de la norma. La fuerza de este discurso puede medirse, tal vez, en el hecho de que las Apuntaciones críticas sobre el lenguaje bogotano de Cuervo tuvieron en vida de su autor seis ediciones actualizadas y se puede considerar una especie de best-seller de la época. En la Correspondencia entre Caro y Cuervo una de las menciones más frecuentes es a las ventas de la obra y a la necesidad de sacar más ejemplares o nuevas ediciones. ${ }^{3}$ Como la "Urbanidad de Carreño" (González

\footnotetext{
${ }^{3}$ Véanse las diversas cartas de Caro a Cuervo desde que este último salió de Colombia en 1878 para radicarse en París; en Miguel Antonio Caro, Epistolario. Correspondencia con don Rufino J. Cuervo y don Marcelino Menéndez y Pelayo.
} 
Stephan), las Apuntaciones pueden haber servido como manual para las nuevas clases. Se convirtieron en norma de comportamiento en el habla, indicaban la forma de acceder a las esferas sociales de los letrados: a pesar de la exigua modernidad, hubo migraciones fuertes del campo a la ciudad (que pueden haber sido motivadas también por la violencia y no necesariamente por las transformaciones modernas), pero de todas maneras hay un sector móvil de la población que puede haber visto las Apuntaciones como un medio de acceder al buen uso del lenguaje, requisito indispensable para tener acceso a la ciudad letrada y de ahí al poder.

En la crónica de su viaje por Colombia entre 1881 y 1882, el argentino Miguel Cané encomia el trabajo filológico de Caro y su traducción de Virgilio, que se cuenta entre las más elogiadas en la lengua castellana. Sin embargo, disiente Cané del pensamiento de Caro en otros puntos:

El señor Caro es en política, en religión y en literatura el tipo más acabado de conservador,
dando a esa palabra toda la extensión de que es suceptible. Nada tengo que ver con sus
ideas sobre la marcha de las cosas en Colombia, ni con las respetabilísimas inspiraciones
de su conciencia; pero cae bajo el dominio de la crítica su apasionamiento ilimitado por
las cosas que fueron la glorificación constante del pasado, del pasado español, contra todas
las aspiraciones del presente, aun del presente español. Si la casualidad ha hecho que el
cuerpo del señor Caro venga a aumentar la falange humana en suelo colombiano, su
espíritu ha nacido, se ha formado y vive en pleno Madrid del siglo XVI (Cané 125).

El historiador Malcolm Deas señala que "la gramática, el dominio de las leyes y de los misterios de la lengua, eran componente muy importante de la hegemonía conservadora que duró de 1885 hasta 1930, y cuyos efectos persistieron hasta tiempos mucho más recientes" (Deas 28). Estos elementos eran más importantes que el dinero o la posesión de tierras. De hecho, según Deas, el dominio de la gramática parecía ser uno de los requisitos indispensables para acceder al poder político. Casi todos los gramáticos, pero Caro principalmente, provenían de familias que habían formado parte de las huestes de letrados durante la Colonia, se habían inscrito gracias a ello en el proceso político de la República después de la Independencia, sin que fuera necesario legitimar su derecho a la conducción de la nación por otras vías que el uso correcto de la letra. En busca del significado de esa preocupación por el idioma, Deas considera que más allá de que la conservación de la lengua fuera la posibilidad de mantener la comunicación entre los hispanoamericanos (la misma preocupación de Bello), "el interés radicaba en que la lengua permitía la conexión con el pasado español, lo que definía la clase de república que estos humanistas querían" (Deas 47).

Los veredictos de Cané en 1883 y de Deas en 1993 coinciden: es el pasado español el que se considera un ideal de república para Caro y que será compartido por sus gramáticos, "contra todas las aspiraciones del presente, aun del presente español", como afirma Cané. El principal vínculo que ha creado Caro con España es la fundación en 1872 de la Academia Colombiana de la Lengua, corresponsal de la española y la primera que se crea en el continente. Para su fundación se estableció que el número de miembros de la Academia sería de doce "como conmemorativo de las doce casas que los conquistadores, reunidos en la llanura de Bogotá el seis de agosto de 1538, levantaron como núcleo de la futura ciudad" (Deas 32). Como es sabido, éstas doce casas (más bien chozas) eran a su vez conmemorativas 
de los doce apóstoles. No habría podido ser más simbólica la fundación de la ciudad letrada de los gramáticos: repite el gesto de la fundación de la ciudad de los conquistadores, que a su vez remitió al símbolo cristiano. Signos que remiten a otros signos. El proyecto político, el religioso y el lingüístico recogidos en un sólo símbolo que lo será de la nación.

$\mathrm{El}$ grupo de los gramáticos es pequeño y cerrado. Apenas supera el número de los académicos de la lengua. Es propio de la cultura bogotana, aunque no todos sean en sentido estricto de Bogotá, (Deas 34) y tiene muy poco o nada que ver con las demás culturas de Colombia. La república humanista que querían era ante todo un proyecto en el orden de las ideas. ¿Cómo entender, entonces, que la visión de mundo de estos hombres sea la que se haya impuesto como el proyecto político de nación para Colombia en el momento en que las ideas de la modernidad europea, racionalista e instrumental, son prácticamente hegemónicas? ¿Más aún si se tiene en cuenta que es un proyecto que se da sólo entre letrados, rodeados de una vasta población analfabeta, en un país fragmentado geográfica y políticamente?

Una posible lectura de este fenómeno pasa por La ciudad letrada de Ángel Rama. Por lo que señala como el lugar que los letrados fueron creando para sí, una ciudad amurallada que, según Rama, debe llamarse así "porque su acción se cumplió en el prioritario orden de los signos y porque su implícita calidad sacerdotal contribuyó a dotarlos de un aspecto sagrado, liberándolos de cualquier servidumbre con las circunstancias" (Rama 25).

En 1881, por la misma época en que Cané visita Bogotá, Miguel Antonio Caro lee en el ámbito exclusivo de la Academia Colombiana de la Lengua el discurso de la Junta Inaugural titulado "Del uso en sus relaciones con el lenguaje" (Estudios de crítica literaria $y$ gramatical). La preocupación principal de su autor es señalar la importancia de la labor de la Academia como guía justa en cuestiones de lenguaje. El trabajo de la institución se considera, sin embargo, parte fundamental de la conducción de la nación. Y los ejemplos de Caro insisten en este punto. El uso correcto de la lengua remite no sólo al orden gramatical. En la lengua se consignan el orden divino, la moral y por tanto la conducción de los pueblos.

"Confundidas están, hemos dicho, en el cultivo de una lengua, la pureza de sus formas y la pureza de sus particulares ideas", afirma en el artículo sobre los "Diccionarios castellanos" (Caro, Estudios 194). Y "si todas las lenguas modernas están cristianizadas, ninguna abunda en sentido espiritual como la castellana, cuya principal riqueza se registra juntamente que en su teatro, eminentemente espiritual, en sus libros religiosos" (191). Difícil saber en esta forma de argumentación, cuál es el huevo y cuál la gallina. ¿Es más pura la lengua por su calidad cristiana? ¿O es más cristiana por su pureza? ¿En sus libros religiosos se aprecia la riqueza por su uso de la lengua, o se aprecia la riqueza de la lengua por estar en función de lo religioso? La argumentación de Caro, salpicada siempre de menciones eruditas, va en ese tipo de círculo: las cosas son buenas porque son católicas, son católicas cuando son buenas.

En sus escritos, la defensa del buen lenguaje es una forma de evitar una caída en la barbarie, es agente civilizador. Para Caro rige como civilización el pensamiento católico. La barbarie será cualquier caída en ideas liberales y desconfía en todo momento del consenso de la mayorías, tanto en asuntos de lengua como de política. En una carta a Rufino José Cuervo le promete un artículo sobre el diccionario de este último que "será más 
filosófico que literario. La idea será que una obra como su Diccionario de usted y otras semejantes no hubieran podido componerse, ni aun concebirse, bajo la influencia de los falsos principios que dominaban en el siglo XVIII, cuando se creía que el lenguaje era cosa de capricho, y la gramática reglamento revolucionario; y de aquí tomaré pie para mostrar el parentesco entre la filología de la Enciclopedia y la política de la Revolución francesa" (Caro, Epistolario 197). Desafortunadamente, no desarrolló Caro esas ideas en el artículo. Hizo, más bien, un recuento histórico de los diccionarios españoles y puso el énfasis ideológico ante todo en la buena moral de los ejemplos y en los peligros que corre el pensamiento cristiano ante enemigos que "quieren forzar el sentido de las palabras; pretenden desnudarlas de las galas adquiridas y azotarlas con el látigo de sus impías definiciones como flagelaban los tiranos a las vírgenes cristianas" (Caro, Estudios 191).

El sentido de las palabras está sujeto, por supuesto, a transformaciones en la historia. Y para saber cuál es el uso y la acepción correcta es necesario remontarse al pasado, a aquellos momentos de mayor grado de civilización. Para saber cuáles son estos momentos, de nuevo Caro usa su argumentación cíclica: la lengua muestra en estos momentos mayor riqueza y es difícil saber si es eso lo que distingue el grado de civilización o si tal vez por ser más civilizado un momento dado de la historia también el uso de la lengua presenta mayor riqueza. De cualquier manera, a los exabruptos de las flosofías utilitaristas y sensualistas, llamadas ciencias bárbaras, "es preciso oponer la sanción por los siglos de las acepciones espirituales de las voces consagradas solemnemente en los diccionarios". Para que el uso de la lengua sea moralmente correcto las palabras deben ser usadas teniendo en cuenta esos sentidos que han tenido en la historia, para poder distinguir aquellas instancias en que remiten a ideas moralmente correctas. En el origen de la lengua está Dios. La tarea de hacer etimologías y definiciones es "de moral interés, de mérito científico y de literaria erudición y tino". Y son de moral interés "porque las lenguas son cuerpos vivientes que respiran las ideas con que se connaturalizan. De aquí lo sagrada que es el habla humana". Es deber de eruditos y gramáticos proteger, cuidar, limpiar, fijar y dar esplendor a los sentidos de las palabras para evitar que expresen ideas contrarias a la moral. Pues en las transformaciones que van sufriendo los vocablos "ennobleciéndose la visión mental, resultan antítesis tan bellas y profundas, como virtud inerme, virginidad fecunda; [...] corrompiéndose el entendimiento, combinaciones tan repugnantes, $\tan$ incorrectas como moral sensualista o egoísmo virtuoso" (Caro, Estudios 190).

Caro organiza una estrategia en la que adopta la gramática como una ciencia, en el sentido mismo que le da el positivismo contra el cual lucha, para sustentar con ella su ideología política y religiosa. El hecho de que sólo unos pocos tengan acceso a las disquisiciones gramaticales opera eficazmente como instrumento de exclusión. La erudición que despliega en todo momento, y que suele distraer del curso de las argumentaciones, confunde y a la vez avala. Difícil enfrentarse a tanto conocimiento de los clásicos latinos, de los gramáticos contemporáneos, a tanta regla y norma, a tanta explicación y disquisición. La forma discursiva que Caro representa se constituye en signo de distinción simbólica y de legitimación política en las últimas dos décadas del siglo XIX en Colombia. Hasta muy entrado el siglo XX será la forma hegemónica y sus huellas pueden percibirse aun hoy en día (Galvis; López de la Roche). La gramática, el regimen de construcción, el diccionario y la norma son, sin embargo, los rasgos superficiales que esconden lo que está a la base de 
este discurso. Por encima, o desprendido del orden, o mejor, del desorden real de las cosas, se sitúa el orden de los signos. Según Rama, ante las amenazas de la democratización, de la inmigración extranjera, la influencia francesa y la fragmentación de las nacionalidades, la ciudad letrada se institucionaliza. En ninguna parte del continente lo hace de manera tan clara como en Colombia con la creación de la Academia de la Lengua. Si lo que caracterizará a la letra en el continente será la "autonomía de los signos y su capacidad para estructurar vastos diseños a partir de sus propias premisas, sustrayéndose a las coyunturas y particularidades del funcionamiento vivo de la realidad" (Rama, La ciudad 83), en ninguna parte será tan radical esta operación de autonomía del signo como en Colombia, en donde los letrados actúan ante todo sobre la lengua misma.

El proyecto político de Caro y de la Regeneración hizo caso omiso del mundo circundante, repitiendo el gesto de la Colonización de América, que según Rama, no respondía a "modelos reales, conocidos y vividos, sino a ideales concebidos por la inteligencia" (Rama, La ciudad 3). La distancia geográfica realmente existente con respecto a España le permite a Caro producir como "parto de la inteligencia" (Rama, con respecto a la ciudad latinoamericana) la ciudad letrada española que eregirá como modelo. El español de España que tanto defiende será para Caro realmente una lengua registrada en libros, no la lengua que oye hablar a su alrededor. Desde la aldeana Bogotá concibe un proyecto de nación sin haber visto jamás su geografía, establece un castellano como norma que no es hablada siquiera por él mismo, erige como modelo una república creada a partir de lecturas seleccionadas según un criterio moral y católico.

Los gramáticos, en alianza con los prelados, conforman una ciudad letrada que es una ciudad amurallada a la que se ingresa por vías de la construcción y el régimen gramatical. Una ciudad en donde la letra se utiliza para hablar de la letra, para regularla y normativizarla. Fuera de esta ciudad letrada se ubica el país real. El regimen de la letra excluye lo que se dice fuera de la ciudad letrada, porque no se dice correctamente. Cuando Lorenzo Marroquín, hijo del expresidente gramático José Manuel Marroquín, escribió una novela satirizando las costumbres de la época de la presidencia de Marco Fidel Suárez, la respuesta del presidente, gramático a su vez, fue un tratado de ciento cincuenta páginas exponiendo los errores gramaticales de la obra. Mientras en el resto del continente las ideas modernas van entrando a todas las capas de la sociedad, se modernizan los estados, las ciudades, la educación, las costumbres, en Colombia se cierra el país. Para ser modernos hay que ubicarse fuera de la ciudad letrada. Gran parte de la producción literaria del país, todo aquello que se produce en las distintas regiones, quedará excluido del cánon que los gramáticos logran conformar a través de la educación católica que se impartirá en los colegios.

En apariencia, la literatura logra la autonomía relativa que se observa a finales del siglo XIX en todo el continente gracias, entre otras cosas, a la división del trabajo intelectual (Henríquez Ureña; Rama, Rubén Darío y el modernismo; Ramos). Pero en Colombia, los políticos son gramáticos y poetas. Aunque pareciera que puedieran deslindar una actividad de otra, el pensamiento coherente de Caro, en el que todos los elementos se conjugan como legitimación directa del poder, arroja sombras incluso sobre la poesía artepurista y relativamente autónoma de José Asunción Silva. Deslindar lo literario de lo político es parte del discurso excluyente de los gramáticos. Acceder a las altas esferas de la poesía es una 
de las formas de ingreso a la ciudad letrada, que no se desvincula del poder político. Quien pertenezca a la ciudad letrada no puede disentir en el interior de ésta. Toda rebelión implica una exclusión.

Dos notables excepciones en la Colombia de fin de siglo fueron Baldomero Sanín Cano, rival de Caro y foco de ataques por parte de éste, y el general Rafael Uribe Uribe, que siguió en su empeño por demostrar que los elementos que Caro y sus seguidores adoptaron como las bases del pensamiento conservador eran algo que compartían todos los colombianos, según se entendía la ciudadanía en el momento, y por tanto no podían ser tema de discusión política: la lengua y la religión. Uribe murió asesinado en 1914 en las escaleras del Congreso. La ciudad letrada de Caro no discutía ideas: censuraba, sancionaba, prohibía y usaba la violencia.

Así se va configurando el lugar de la letra en la cultura: la letra no es el camino para buscar, debatir, cotejar, postular; se erige como lugar de exclusión. Desde la letra no se piensa el país real sino que se impone el país que conciben unos pocos como país ideal. Pensar fuera de la ciudad letrada exige acudir a aquello que no se someta al orden de la letra. Creo que gran parte de las letras colombianas son, en este sentido, anti-letradas. Buscar cómo viven, hablan y piensan los que están fuera de la ciudad letrada implica una exclusión de ella. Los escritores mismos en muchos sentidos son también unos excluidos y gradualmente irán excluyendo todo aquello que defienden los letrados de la ciudad amurallada tras diccionarios, gramáticas y libros de oración.

Del amor y otros demonios de Gabriel García Márquez (1994) invita a una lectura como metafórica de aquello que genera la ciudad letrada. El relato tiene lugar en Cartagena de Indias en 1749 después del sitio de los ingleses. Según el ambiente que crea García Márquez, los letrados de la ciudad —el clero y la nobleza colonial — siguen amurallados, encerrados dentro de las imposiciones que recaen sobre ellos por el mismo régimen de exclusión que han impuesto sobre la población. El Marqués de Casalduero teme ataques de sus esclavos y se encierra en su quinta, mientras su servidumbre se mueve libremente no sólo por la casa sino por la ciudad. Igualmente, dentro de la ciudad amurallada de Cartagena impera la intolerancia, las normas rígidas de los letrados. Fuera de la muralla, en Getsemaní, el barrio de los esclavos, se da, por así decirlo, la vida real de la ciudad. El mundo letrado es un mundo de encierros, de restricciones y normas. Será fuera de él donde se podrán desarrollar las libertades de los individuos, pero éstas se posicionan como infracción a las normas. En el relato de García Márquez casi todos los personajes buscan caminos de felicidad individual, la cual se verá frustrada por las leyes que rigen dentro de la ciudad amurallada. Las normas y restricciones no hacen feliz a nadie y resultan inútiles como forma de contención del otro, bien se trate de otras culturas o de otras formas de pensar.

Más dramático y violento es el relato de Fernando Vallejo, La Virgen de los Sicarios (1994), en donde claramente se unen la gramática, la religión y la violencia. Un gramático regresa, después de años de exilio, a una Medellín azotada por la violencia del narcotráfico e inicia una relación amorosa con un sicario. En las primeras partes del relato, el gramático se esmera por explicar el lenguaje de los sicarios, por marcar una diferencia. Poco a poco, va adoptando el reducido vocabulario de su amante y su instrumento de expresión: la ametralladora. Juntos, el gramático y el sicario recorren la ciudad eliminando los enemigos del gramático: taxistas que escuchan vallenatos y señoras embarazadas que siguen 
reproduciendo una raza degenerada. Por supuesto, no será el gramático quien empuñe el arma. Se encargará únicamente de legitimar con argumentos de exclusión la elección de sus víctimas. El sicario las mata sin importarle quiénes sean o por qué han de morir. A este clima de violencia se unen, como partes integrales, consecuencias o causas lógicas de la situación, la devoción a la Virgen de los Sicarios y las fuertes lealtades familiares hacia la cultura antioqueña.

Las rencillas partidistas, que siempre funcionaron como base de la política, mantuvieron al país fragmentado sin que hubiera un imaginario de nación que cubriera a todos por encima de sus fracciones. No fue a través de la escuela ni de la pobre difusión de la letra normativizada y regulada como los colombianos fueron imaginando la nación. Cuando hacia 1930 se hicieron reformas sociales en el país buscando integrar nuevos sectores de la población a la modernidad, entre otras por vías de la educación —es decir de la letrairrumpió un nuevo medio de comunicación que pasaba por encima de ella: la radio. ${ }^{4} \mathrm{El}$ proyecto de los letrados de la Regeneración operó tan eficazmente como sistema de exclusión de sus contrincantes políticos que la letra no pudo funcionar como espacio para la negociación no violenta de los conflictos sociales o políticos. Para esto siempre se acudió a las armas.

Pensar y estudiar la letra en Colombia no deja, por lo tanto, de plantear paradojas. Remitirse al grupo de los gramáticos y en especial a Miguel Antonio Caro es un intento de desandar ese camino de la letra. Pero, como los gramáticos, estoy en el ámbito de la letra y no fuera de ella. Y trabajo dentro de la ciudad amurallada que ellos nos legaron. Ángel Rama dice sobre la producción de los letrados en la Colonia que "productores y consumidores debieron ser los mismos" (26). Esta afirmación de Rama me remite a una observación de Edward W. Said sobre los trabajos académicos que parecieran ser leídos tan sólo por colegas y el énfasis en que cuando algo se escribe es para alguien, para un Otro (Said 135-137). Pero, ¿quién es ese otro? A cada paso se plantea la pregunta por la incidencia que pueda tener el pensar la letra desde la letra cuando ésta ha perdido tanto de su peso. Y la necesidad de pensar qué implica, qué hemos perdido, qué hemos ganado con ese cambio. Se plantea en cada giro, en cada esquina, el peligro de caer en nostalgias, en nociones gutembergianas de la cultura, en reivindicaciones trasnochadas de la palabra escrita. También el peligro de creer que no se justifica hacerlo, que no tiene sentido.

Cuando estoy terminando de escribir esto, en agosto de 1996, en Colombia reina el caos político y social. En estos días en la ciudad de Apartadó, Antioquia, al norte del país, la alcaldesa Gloria Cuartas se encontraba en una escuela explicando a cien niños las actividades que se iban a realizar durante la Semana por la Paz. En Colombia hay casi tantas semanas por la paz, marchas por la paz, acuerdos de paz, convenciones sobre la paz, libros sobre la paz, discursos por la paz, como víctimas de la violencia. Cuando la alcaldesa llevaba una hora trabajando con los niños en el patio del colegio, llegaron dos hombres jóvenes armados y con el rostro descubierto. Agarraron a César Augusto Rivera, de doce años de

\footnotetext{
${ }^{4}$ Ver Jesús Martín Barbero, De los medios a las mediaciones. Comunicación cultura y hegemonía y Brunner. Ambos sotienen, al contrario de discursos letrados, que fue a través de los medios masivos de comunicación, sobre todo la radio y el cine, y más tarde la televisión, que las masas latinoamericanas accedieron gradualmente a la modernidad.
} 
edad, le dieron un golpe en el estómago y le cortaron la cabeza con un machete. Sacaron sus revólveres y, mientras agitaban la cabeza, lanzaban tiros al aire. La alcaldesa y los niños se refugiaron en las aulas. La balacera se prolongó durante casi tres horas.

Nadie tiene palabras. Cada semana en Colombia se comete un crimen de este orden. Cada semana hay cientos de secuestrados y asesinados, torturados y violados. No hay proclamas ni discursos después de un crimen, nadie tiene que justificar o legitimar sus actos con palabras. Las armas se encargan de ello. ¿Cómo y para qué pensar la relación entre la palabra y el poder? Siempre está la sospecha de que perdimos la palabra cuando ésta se amuralló tras las gramáticas y los diccionarios, la moral cristiana y el principio incuestionado de autoridad del Estado y la Iglesia. La utopía consiste en intentar desandar ese camino, recuperarla, sacarla de ese lugar. Y hacerlo con palabras.

\section{OBRAS CITADAS}

Anderson, Benedict. Imagined Communities. Reflections on the Origin and Spread of Nationalism. London: Verso, 1983.

Bhabha, Homi (ed.). Nation and Narration. Londres: Verso, 1990.

Brunner, José Joaquín. América latina: cultura y modernidad. México: Grijalbo, 1992. Cané, Miguel. En Viaje. 1881-1882. 1883. Buenos Aires: Editorial Sopena, 1940.

Caro, Miguel Antonio. Estudios de critica literaria y gramatical. Darío Achury Valenzuela, ed. Bogotá: Biblioteca de la Presidencia de Colombia, Imprenta Nacional, 1955. Epistolario. Correspondencia con don Rufino J. Cuervoydon Marcelino Menéndez y Pelayo. Publicaciones de la Academia Colombiana Correspondiente de la Española. Tomo II. Bogotá: Editorial Centro S.A., 1941.

Cuervo, Rufino José. Apuntaciones críticas sobre el lenguaje bogotano. 1867. Bogotá: Instituto Caro y Cuervo, 1954.

Deas, Malcolm. "Miguel Antonio Caro y amigos: gramática y poder en Colombia". Del poder y la gramática y otros ensayos sobre historia, política y literatura colombianas. Bogotá: Tercer Mundo Editores, 1993. 25-60.

Galvis, Ligia. Filosofia de la Constitución colombiana de 1886. Bogotá (sin datos editoriales), 1986.

García Márquez, Gabriel. Del amor y otros demonios. Bogotá: Norma, 1994.

GonzálezStephan, Beatriz. "Modernizacióny disciplinamiento. La formación del ciudadano: del espacio público y privado". Beatriz González Stephan, Javier Lasarte, Graciela Montaldo y María Julia Daroqui (comps.) Esplendores y miserias del siglo XIX. Cultura y sociedad en América Latina. Caracas: Monte Ávila Editores, 1995. 431455.

Henríquez Ureña, Pedro. Las corrientes literarias en la América Hispana. México: Fondo de Cultura Económica, 1974.

Jaramillo Uribe, Jaime. "Caro y Alberdi: dos posiciones frente al problema de la orientación cultural de Hispanoamérica en el siglo XIX". La personalidad histórica de Colombia y otros ensayos. Bogotá: El Áncora Editores, 1994. 48-71.

López de la Roche, Fabio. "Cultura política de las clases dirigentes en Colombia: 
permanencias y rupturas". Fabio López de la Roche, comp. Ensayos sobre cultura politica colombiana. Bogotá: CINEP, 1990. 99-204.

Martín Barbero, Jesús. De los medios a las mediaciones. Comunicación, cultura y hegemonía. 1987. México: Ediciones G. Gili, 2a. Edición 1991.

"Secularización, desencanto y reencantamiento massmediático". Pre-textos. Conversaciones sobre la comunicación y sus contextos. Cali: Centro Editorial Universidad del Valle, 1995. 177-192.

Nieto Arteta, Luis Eduardo. "La regeneración y la organización nacional de Colombia". Economía y cultura en la historia de Colombia. 1942. Bogotá: El Áncora Editores, 1987. 274-299.

Pécaut, Daniel. L'Ordre et la Violence. Evolution socio-politique de la Colombie entre 1930 et 1953. Paris: Editions de l'Ecole des Hautes Etudes en Sciences Sociales, 1986. Traducción española: Orden y Violencia: Colombia 1930-1954. Bogotá: CEREC Siglo XXI, 1987.

Rama, Ángel. Rubén Darío yel modernismo. 1970. Barcelona: Alfadil Ediciones, 1985. La ciudad letrada. Hannover, N.H.: Ediciones del Norte, 1984.

Las máscaras democráticas del modernismo. Montevideo: Fundación Ángel Rama, 1985.

Ramos, Julio. Desencuentros de la modernidad en América Latina. Literatura y politica en el siglo XIX. México: Fondo de Cultura Económica, 1989.

Romero, José Luis. Latinoamérica: las ciudades y las ideas. 1976. México: Siglo XXI, 3a. Edición, 1984.

Sarlo, Beatriz. Una modernidad periférica: Buenos Aires 1920 y 1930. Buenos Aires: Ediciones Nueva Visión, 1988.

Escenas de la vida posmoderna. Intelectuales, arte y videocultura en la Argentina. Buenos Aires: Ariel, 1994.

Said, Edward W. "Opponents, Audiences, Constituencies and Community”. Postmodern Culture. Hal Foster, ed. Londres, Concord, Mass: Pluto Press, 1990. 135-159.

Schwarz, Roberto. Misplaced Ideas. Essays on Brazilian Culture. London: Verso, 1992.

Torres García, Guillermo. Miguel Antonio Caro, su personalidad política. Madrid: Ediciones Guadarrama, S.L., 1956.

Tovar González, Leonardo. "Tradicionalismo y neoescolástica". La filosofia en Colombia. Germán Marquínez Argote, Roberto Salazar Ramos et. al. Bogotá: Editorial el Búho. 2a Edición, 1992.

Vallejo, Fernando. La Virgen de los sicarios. Bogotá: Santillana, 1994. 
